\title{
Tmem30a Plays Critical Roles in Ensuring the Survival of Hematopoietic Cells and Leukemia Cells in Mice
}

Ning $\mathrm{Li},{ }^{* \dagger}$ Yeming Yang, ${ }^{\dagger}$ Cailing Liang,${ }^{* \dagger}$ Qiang Qiu, ${ }^{* \dagger}$ Cong Pan, ${ }^{* \dagger}$ Mengyuan $\mathrm{Li},{ }^{* \dagger}$ Shengyong Yang, ${ }^{\dagger}$ Lijuan Chen, Xianjun $\mathrm{Zhu}^{+\delta}$ and Yiguo $\mathrm{Hu}^{* \dagger}$

Accepted for publication February 27, 2018.

Address correspondence to Xianjun Zhu, Ph.D., Sichuan Provincial People's Hospital, University of Electronic Science and Technology of China, Chengdu, Sichuan 610072, China; or Yiguo Hu, Ph.D., No. 17, Third part of Ren-Min-Nan Rd Chengdu, Sichuan 610041, China. E-mail: xjzhu@uestc.edu.cn or huyiguo@scu.edu.cn.

\begin{abstract}
The fundamental structure of eukaryotic cell plasma membrane is the phospholipid bilayer, which contains four major phospholipids. These phospholipids are asymmetrically distributed between the outer and inner leaflets. P4-ATPase flippase complexes play essential roles in ensuring this asymmetry. We found that conditional deletion of Tmem30a, the $\beta$ subunit of P4-ATPase flippase complex, caused pancytopenia in mice. Tmem30a deficiency resulted in depletion of lineage-committed blood cells in the peripheral blood, spleen, and bone marrow. Ablation of Tmem30a also caused the depletion of hematopoietic stem cells (HSCs). HSC RNA sequencing results revealed that multiple biological processes and signal pathways were involved in the event, including mammalian target of rapamycin signaling, genes for HSC stemness, and genes responding to interferons. Our results also revealed that targeting Tmem30a signaling had therapeutic utility in BCR/ABL1-induced chronic myeloid leukemia. (Am J Pathol 2018, 188: 1457-1468; https://doi.org/10.1016/j.ajpath.2018.02.015)
\end{abstract}

Plasma membrane is a fundamental structure of eukaryotic cells. The plasma membrane consists of a phospholipid bilayer, which contains four major phospholipids [phosphatidylcholine, phosphatidylethanolamine (PE), phosphatidylserine (PS), and sphingomyelin], glycolipids, and cholesterol. ${ }^{1}$ These phospholipids are asymmetrically distributed between the outer and inner leaflets of plasma membrane. P4-ATPase flippase complexes play essential roles in ensuring the asymmetric distribution of phospholipids. ${ }^{2}$ The P4-ATPase flippase complex is composed of a catalytic $\alpha$ subunit and an accessory $\beta$ subunit. ${ }^{1,2}$ The $\alpha$ subunit catalyzes the hydrolysis of ATP, and the $\beta$ subunit assists in binding of the phospholipid substrate. ${ }^{2}$ P4-ATPase flippase complexes transport aminophospholipids from the outer to the inner leaflets by using ATP. ${ }^{1}$

P4-ATPases are critical for various biological processes, such as blood coagulation regulation, vesicular protein transport, the recognition of apoptotic cells, and sperm capacitation. $^{3-6}$ P4-ATP flippase complexes also play roles in the regulation of cell migration through mediating the translocation of PE at plasma membrane. ${ }^{7}$ Phospholipid translocation seems also to be implicated in vesicle formation and in uptake of lipid signaling molecules. ${ }^{2}$ Deficiency of $\alpha$ subunits, such as $A T P 8 B 1, A T P 8 A 2$, and $A T P 11 C$, leads to various human diseases. ${ }^{8-11}$ Deficiency of Atpllc causes B-cell lymphopenia, anemia, and intrahepatic cholestasis in mice. ${ }^{12-15}$ However, the functions of $\beta$ subunits of P4-ATPase flippase complexes remain elusive.

Recently, an inducible or tissue-specific deletion of Tmem30a mouse model was generated. ${ }^{16}$ Tmem $30 \mathrm{a}$ belongs to

N.L. and Y.Y. contributed equally to this work.

Supported by Natural Science Foundation of China grants 81541092 (Y.H.), 21561142003 (X.Z.), 81770950 (X.Z.), and 81470668 (X.Z.); National Key Basic Research Program of China grant 2015 CB554100 (X.Z.); and Department of Science and Technology of Sichuan Province grants 2016TD0009 and 2017TJPT0010 (X.J.Z.).

Disclosures: None declared. 
the $\beta$ subunit family members of PS flippase, one kind of the P4-ATPase family complexes. ${ }^{16}$ PS flippase predominantly transport PS and a lesser PE. ${ }^{2}$ PS is primarily located in the inner cytoplasmic leaflet, and PS flippase transports PS from the exoplasmic to the cytoplasmic leaflet of cell membrane. ${ }^{17-19}$ Deficiency of Tmem30a causes an embryonic lethal phenotype. ${ }^{16}$ Two studies about the functions of Tmem30a have been performed in the retina and liver, respectively, by using Tmem30a tissue-specific deletion mouse models. ${ }^{16,20}$ Deletion of Tmem30a resulted in a loss of PS flippase activity and exposure of PS on cell outer surface. ${ }^{16,20}$ Tmem30a deficiency in mouse cone cells results in loss of cone cells and impaired photopic electroretinogram responses in the retina. ${ }^{16}$ Currently, the physiologic roles of Tmem30a in hematopoietic cells are unknown. Hematopoietic cells consist of many cell types with specialized functions and are organized as a cellular hierarchy. ${ }^{21}$ In adults, hematopoietic stem cells (HSCs) are evidenced at the apex, which give rise to all the other blood cells through the process of hematopoiesis. ${ }^{21}$ Blood cells play important roles in maintaining the body's functions. In fields of hematopoietic neoplasm, the roles of Tmem30a are also not defined, especially its roles in leukemia stem cells (LSCs). It has become apparent that the initiation and propagation of chronic myeloid leukemia (CML) are driven by LSCs. $^{22}$ Thus, it becomes essential to eliminate LSCs completely to cure CML. ${ }^{22}$

In this study, we focused on the roles of Tmem30a in the hematopoietic system. Using a Tmem30a inducible knockout mouse model, we found that Tmem30a is essential for the survival of hematopoietic cells. Tmem30a deficiency markedly decreased all lineage-committed blood cells and HSCs and impaired the survival of LSCs of BCR/ABL1-transduced CML.

\section{Materials and Methods}

\section{Mice}

Conditional gene-targeted Tmem $30 \mathrm{a}^{\text {flox/flox }}$ mice were generated as described previously. ${ }^{16}$ Briefly, to delete Tmem30a in hematopoietic cells in vivo, Tmem30 $\mathrm{a}^{\text {flox/flox; }}$ CAG-Cre-ER (named Tmem $30 a^{-/-}$) mice were generated by breeding Tmem $30 \mathrm{a}^{\text {flox/flox }}$ mice with CAG-Cre-ER transgenic mice. ${ }^{23}$ Cre expression was induced by i.p. injection of three doses of tamoxifen at a daily dosage of $25 \mathrm{mg} / \mathrm{kg}$ body weight at 8 weeks after birth. Littermates of CAG-Cre-ER [wild-type (WT)] mice were used as control and treated at same injection as Tmem $30 a^{-/-}$mice. All animal studies were performed in accordance with the guidelines approved by the Institutional Animal Care and Use Committees of Sichuan University and Sichuan Provincial People's Hospital.

\section{Tamoxifen Injection and BM Cell Harvest}

Tamoxifen salt (Sigma, St. Louis, MO) was dissolved in ethanol at a concentration of $10 \mathrm{mg} / \mathrm{mL}$, which was kept in $-20^{\circ} \mathrm{C}$ freezer as a stock solution. Before injection, tamoxifen was further diluted to $1 \mathrm{mg} / \mathrm{mL}$ with corn oil (Sigma). Tmem $30 a^{-/-}$ and $W T$ mice were injected intraperitoneally with a daily dosage of $25 \mathrm{mg} / \mathrm{kg}$ body weight for 3 days. At days 7, 15, and 28 after tamoxifen injection, mice were sacrificed and bone marrow (BM) cells harvested from femurs and tibia for analysis.

\section{Flow Cytometry}

BM cells from tamoxifen-treated mice were incubated in red blood cell lysis buffer ( $\mathrm{pH}$ 7.4) to facilitate the removal of erythrocytes. The percentages of the targeting cell population were determined with flow cytometry after the isolation of single cells. Single cell suspensions were incubated for 30 minutes at room temperature with various combinations of the following cell-surface marker antibodies: B220 for B cells, Gr-1 for myeloid cells, $\mathrm{Cd} 3$ for $\mathrm{T}$ cells, $\mathrm{B} 220^{+} \mathrm{IgM}^{-}$for pro-/pre- $\mathrm{B}$ cell, B220 ${ }^{\text {low }} \operatorname{IgM}^{+}$for immature B cell, B220 ${ }^{\text {high }} \operatorname{IgM}^{+}$for mature B cell, $\mathrm{Lin}^{-} \mathrm{c}-\mathrm{Kit}^{+} \mathrm{Sca}-1^{+}$for $\mathrm{HSCs}, \mathrm{Lin}^{-} \mathrm{c}-\mathrm{Kit}^{+} \mathrm{Sca}-$ $1^{-} \mathrm{CD} 34^{+} \mathrm{CD} 16 / 32^{-}$for common myeloid progenitors (CMPs), $\mathrm{Lin}^{-} \mathrm{c}-\mathrm{Kit}^{+} \mathrm{Sca}-1^{-} \mathrm{CD} 34^{+} \mathrm{CD} 16 / 32^{+}$granulocyte-monocyte progenitor (GMP), and $\mathrm{Lin}^{-} \mathrm{c}-\mathrm{Kit}^{+} \mathrm{Sca}-1^{-} \mathrm{CD} 34^{-} \mathrm{CD} 16 / 32^{-}$ megakaryocyte-erythroid progenitor (MEP). The antibodies were purchased from BD Biosciences (Becton Dickinson, Franklin Lakes, NJ), including PE-CD34. The antibodies were purchased from eBioscience (San Diego, CA), including allophycocyanin (APC)-cyanine 7 (Cy7)-B220, PE-Gr1, PE-Cy7-CD16/CD32, PE-CD34, fluorescein isothiocyanate (FITC)-CD45.2, APC-CD45.1, PE-IgM, FITC-Cd3, Pacific blue- - Lin $^{-}$, PE-Sca-1, and APC-c-Kit.

\section{BM Cell Competition Assay}

BM cells were harvested from 8-week-old B6.SJL-Ptprca$\mathrm{Pepc}^{\mathrm{b} / \mathrm{BoyJ}}$ (CD45.1) mice and Tmem30a ${ }^{-1-}(\mathrm{CD} 45.2)$ mice. $\mathrm{BM}$ cells from CD45.1 and CD45.2 mice were mixed in a ratio of 1:1. CD45.1 mice were subjected to two rounds of 450-cGy $\mathrm{X}$-ray irradiation and injected with $1 \times 10^{6}$ total BM cells $\left(5 \times 10^{5}\right.$ cells of each). After 12 weeks, recipients were randomly divided into two groups. One group was treated with tamoxifen, and another group was treated with placebo (corn oil with ethanol). BM cells were collected and subjected to flow cytometry analysis. The ratio of CD45.1 to CD45.2 cells in recipient $\mathrm{BM}$ was determined with their specific antibodies.

\section{Histopathologic Analysis and Immunohistochemistry}

Tissues were fixed, processed, sectioned, and stained with hematoxylin and eosin by routine methods. Femurs were additionally treated for 1 hour in decalcifying solution (Fisher Scientific, Shanghai, China). Immunohistochemistry was performed according to standard procedures. The rat antimouse Cd19 (EM40308, Huabio, Hangzhou, China) and rat anti-mouse Gr-1 (281-2) monoclonal antibodies were obtained from BD Biosciences; TMEM30A monoclonal antibody (Cdc50-7F4) was a gift from Dr. Robert Molday (University of British Columbia, Vancouver, BC, Canada). 
A

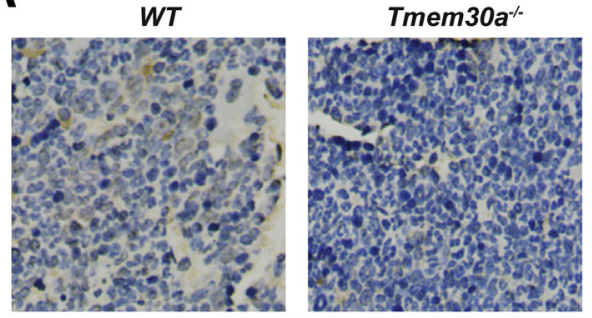

IB: Tmem30a

C
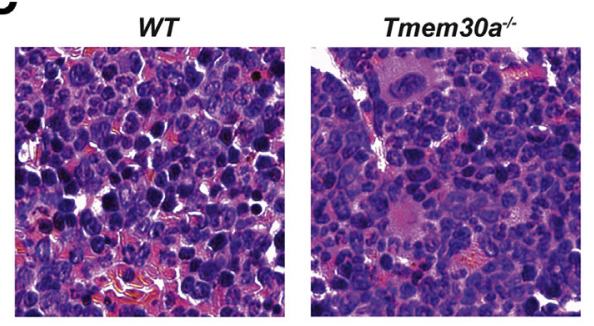

B

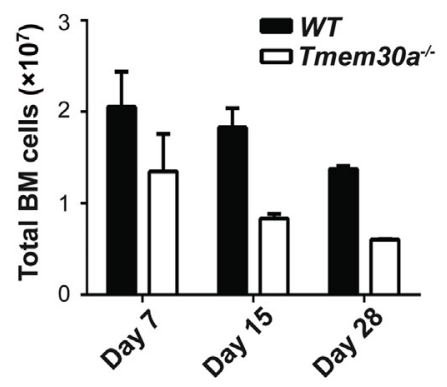

D
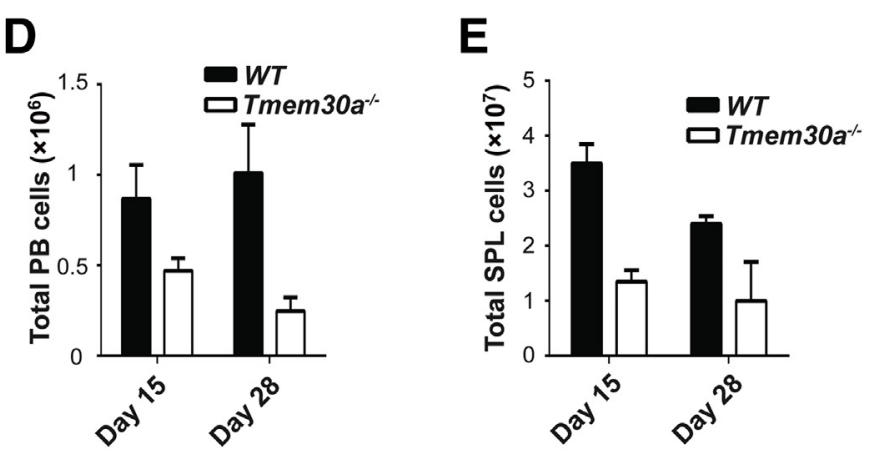

Figure 1 Tmem30a deficiency causes pancytopenia in mice. A: Immunohistochemistry photomicrographs of bone marrow (BM) section of wild-type (WT) and Tmem $30 a^{-/-}$mice treated with tamoxifen for 15 days were stained with Tmem30a. B: Total BM cell counts from femurs and tibia of WT and Tmem30a ${ }^{-/-}$ mice treated with tamoxifen for 7, 15, and 28 days. C: Photomicrographs of hematoxylin and eosin-stained bone sections of WT and Tmem30a ${ }^{-/-}$mice treated with tamoxifen for 15 days. D and E: White blood cell counts in peripheral blood (PB; D) and spleen (SPL; E) at days 15 and 28 after tamoxifen treatment. At least two independent experiments were performed for confirmation. Consistent results were achieved every time. Data are expressed as means \pm SD (B, D, and E). $n=3$ mice. Original magnification, $\times 200$ (A and C). IB, immunoblot.

\section{RNA Sequencing Analysis}

Hematopoietic stem cells $\left[\mathrm{Lin}^{\text {low }} \mathrm{Scal}^{+} \mathrm{c}-\mathrm{Kit}^{+}(\mathrm{LSK})\right.$ cells] were sorted from the BM of $W T$ and Tmem $30 a^{-1-}$ mice at day 7 after tamoxifen injection using a fluorescence activated cell sorter Aria III (Becton Dickinson). Total RNA was extracted from LSK cells using the RNeasy Mini kit (Qiagen, Hilden, Germany). RNA samples were reverse transcribed, amplified using the Ovation Pico WTA System version 2 (NuGEN Technologies, San Carlos, CA), and biotin labeled with the Encore Biotin Module (NuGEN Technologies). RNA sequencing was performed with the Illumina MiSeq system (Illumina, San Diego, CA). Gene set enrichment analysis was performed as previously described. ${ }^{24}$ RNA sequencing data were provided in Supplemental Table S1. Gene signatures were analyzed with Gene Set Enrichment Analysis (GSEA) software version 3.0 (GSEA, http://software.broadinstitute.org/gsea/ index.jsp, last accessed September 9, 2017) in the Molecular Signatures Database (Broad Institute, Cambridge, MA). ${ }^{25,26}$

\section{BCR/ABL1-Transduced CML Mouse Model}

The retroviral vector puro murine stem cell virus-BCR/ ABL1-internal ribosome entry site-enhanced green fluorescent protein (pMSCV-BCR/ABL1-IRES-eGFP) was used to generate virus stocks as described previously. ${ }^{24}$ Briefly, donor mice were pretreated with 5-fluorouracil, $200 \mathrm{mg} / \mathrm{kg}$ (Sigma), through i.v. tail injection. Four days later, BM cells were harvested from donor mouse femurs and tibia. BM cells were prestimulated with $10 \mu \mathrm{g} / \mathrm{mL}$ of IL3 (Novoprotein Scientific Inc., Shanghai, China), $10 \mu \mathrm{g} /$ $\mathrm{mL}$ of IL-6 (Novoprotein), and $50 \mu \mathrm{g} / \mathrm{mL}$ of stem cell factor (Novoprotein). In the next 2 days, BM cells were subjected to two rounds of cosedimentation with retroviral stock at $1000 \times g$ for 90 minutes. The transfected marrow cells were transplanted via tail vein injection into same genetic background recipient mice $\left(0.5 \times 10^{6}\right.$ per mouse $)$ as the donor mice. Recipients received two doses of $450 \mathrm{cGy}$ of X-ray irradiation separated by 3 hours. Leukemia cells and LSCs were determined with viable $\mathrm{GFP}^{+}$cells with $\mathrm{Gr}-1^{+}$or $\mathrm{Lin}^{-} \mathrm{Scal}^{+}{ }^{+}-\mathrm{Kit}^{+}$, respectively.

\section{Statistical Analysis}

All experiments were performed in triplicate and repeated at least twice. Statistical significance was determined by 1-way analysis of variance or $t$-test using GraphPad Prism software version 6 (San Diego, CA). $P<0.05$ was considered statistically significant.

\section{Results}

\section{Tmem30a Deficiency Results in Pancytopenia}

To define the physiologic functions of Tmem30a in the hematopoietic system, the murine Tmem30a gene in adult 
A

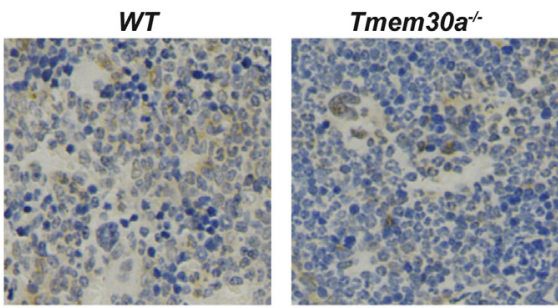

IB: Cd19

C

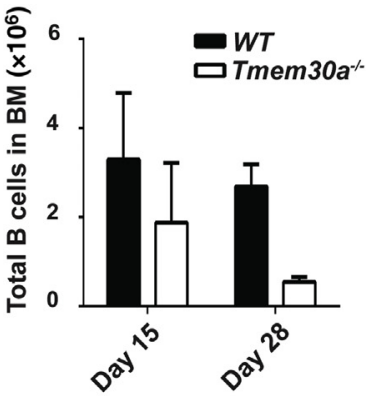

B

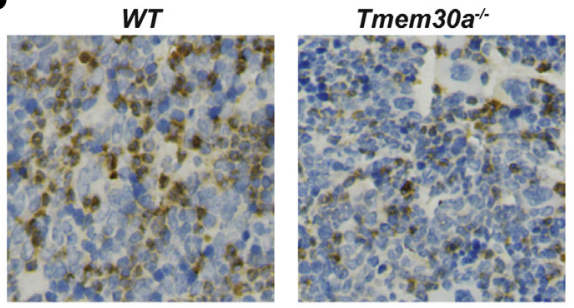

IB: Gr-1

D
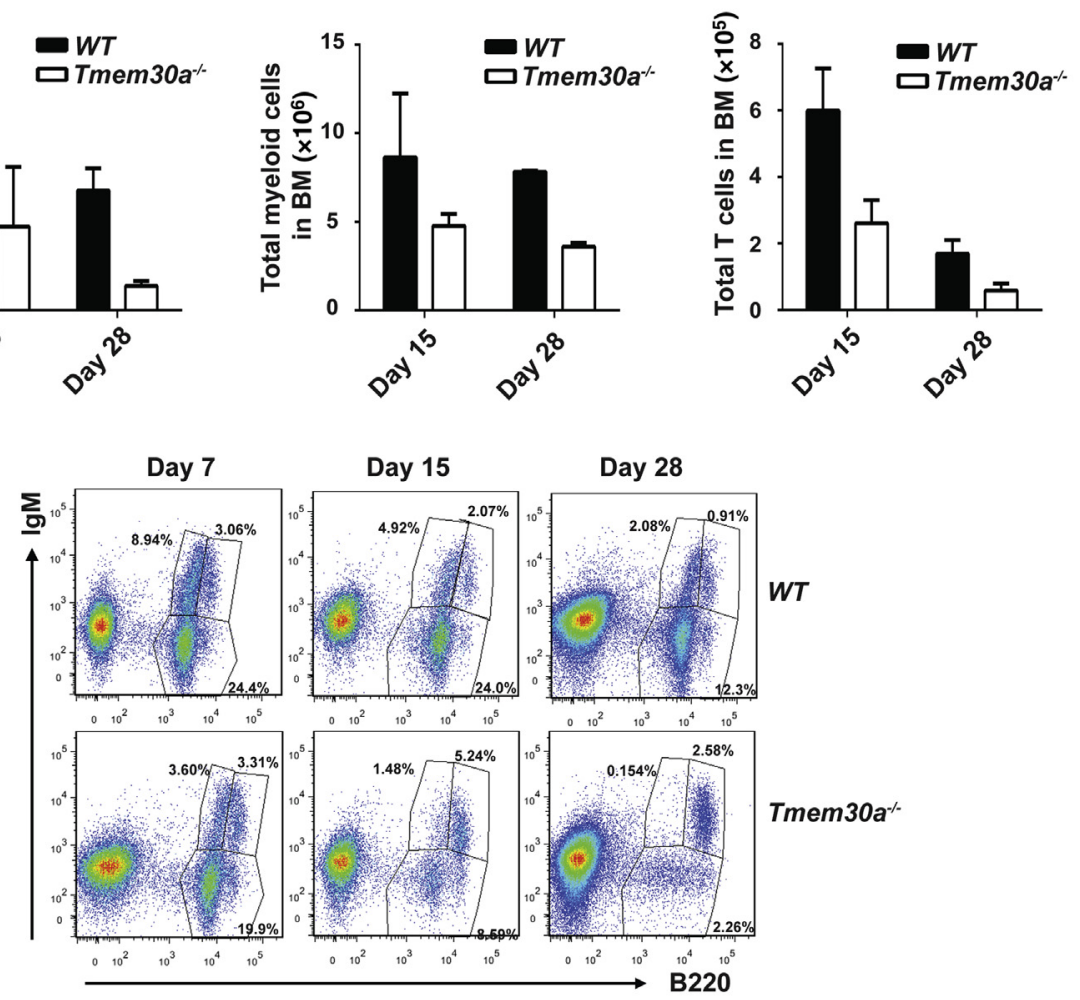

E
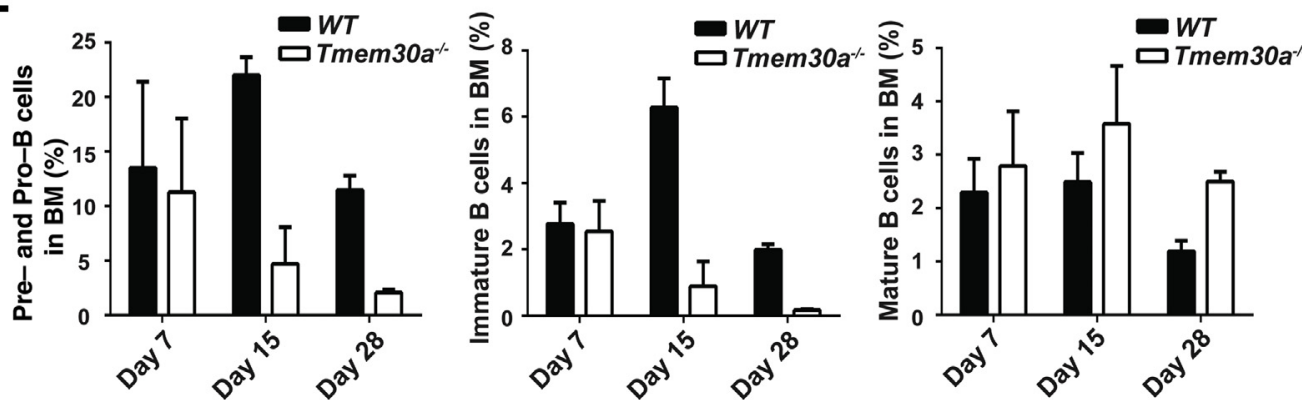

Figure 2 Tmem30a deficiency causes pancytopenia in mice. A and B: Immunohistochemistry photomicrographs of bone marrow (BM) section of wild-type (WT) and Tmem30a ${ }^{-1-}$ mice treated with tamoxifen for 15 days were stained with $\mathrm{Cd} 19$ (A) and Gr-1 (B), respectively. C: The total cell counts of B cells $\left(\mathrm{B} 220^{+}\right)$, myeloid cells $\left(\mathrm{Gr}-1^{+}\right)$, and T cells $\left(\mathrm{Cd}^{+}\right)$in BM after tamoxifen treatment at indicated days. D: Fluorescence-activated cell sorting analysis shows B-cell development stages (pro- and pre-B cell represented with $\mathrm{B}_{22} 20^{+} \mathrm{IgM}^{-}$; immature B cell represented with $\mathrm{B}_{2} 20^{\text {low }} \mathrm{IgM}^{+}$; mature $\mathrm{B}$ cell represented with $\mathrm{B}_{22} 0^{\text {high }} \mathrm{IgM}^{+}$) in BM of WT and Tmem30a ${ }^{-/-}$mice at day 15 after tamoxifen treatment. E: Percentage of pro- and pre-, immature, and mature B cells in BM of WT and Tmem $30 a^{-1-}$ mice at days 7, 15, and 28 after tamoxifen treatment (from left to right). Independent experiments were performed two times (E) or three times (C). Data are expressed as means \pm SD (C and E). $n=3$ mice. Original magnification, $\times 200$ (A and $\mathbf{B})$. IB, immunoblot.

Tmem $30 a^{-1-}$ mice was deleted by three i.p. injections of tamoxifen. Immunohistochemistry against Tmem30a was used to confirm the deletion in BM of the Tmem $30 a^{-1-}$ mice, and their littermates were used as WT control (Figure 1A).
Tmem $30 a^{-1-}$ mice died between 35 and 50 days after tamoxifen injection (data not shown). Tmem $30 a^{-1-}$ mice had a marked decrease in leukocyte counts in $\mathrm{BM}$ with a time-dependent pattern (Figure 1B). Tmem30a deficiency 
A

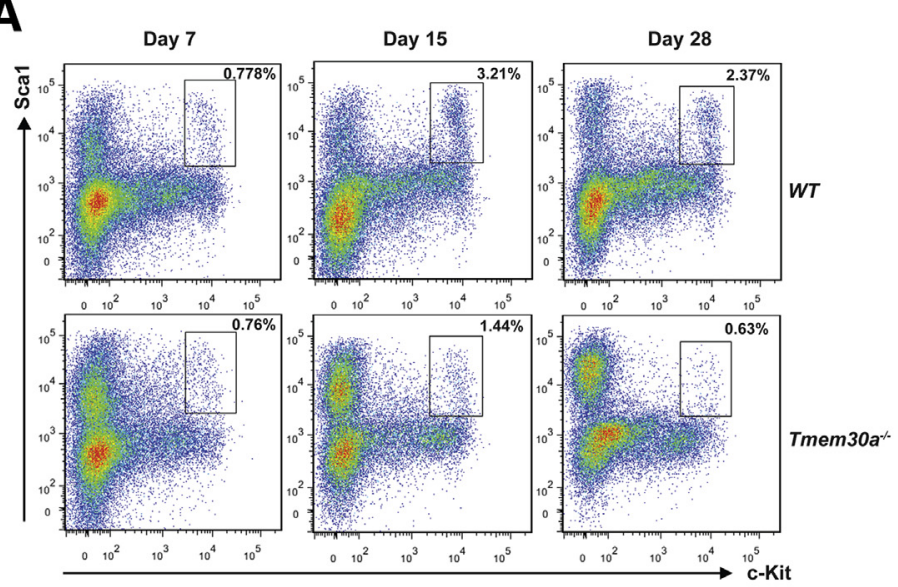

C

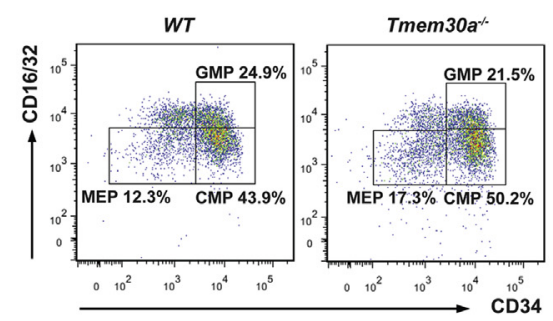

$\mathbf{E}$

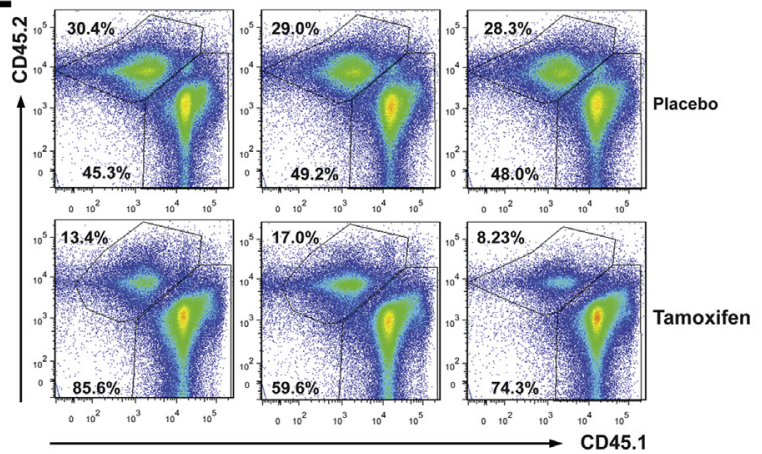

B

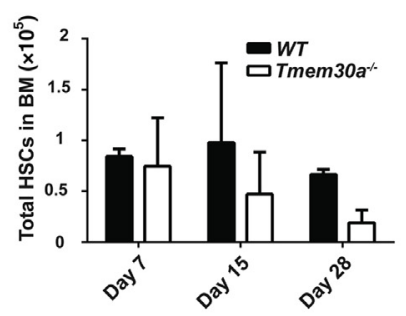

D

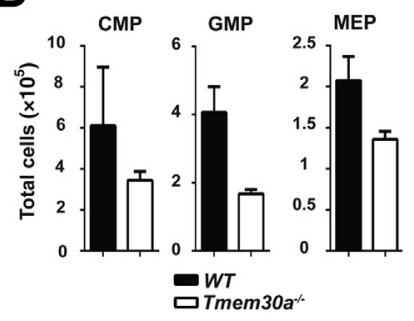

$\mathbf{F}$

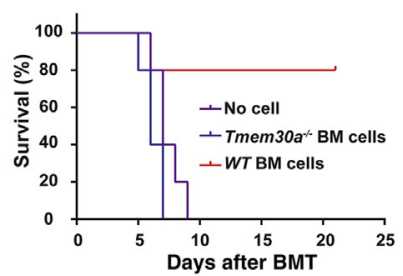

Figure 3 Tmem30a deficiency impairs hematopoietic stem cell (HSC) survival. A and B: The percentages (A) and total numbers (B) of $\mathrm{HSCS}_{(\mathrm{Lin}}{ }^{-} \mathrm{C}-\mathrm{Kit}^{+} \mathrm{Sca}-$ $1^{+}$) are much lower in bone marrow (BM) of Tmem30a ${ }^{-/-}$mice than those in BM of wild-type (WT) mice. C: Common myeloid progenitor (CMP; CD34 ${ }^{+}$Lin ${ }^{-}$Sca$1^{-}$c-Kit ${ }^{+} \mathrm{Cd} 16 / 32^{-}$cell population), granulocyte-monocyte progenitor (GMP; $\mathrm{CD} 34^{+} \mathrm{Lin}^{-} \mathrm{Sca}-1^{-} \mathrm{C}-\mathrm{Kit}^{+} \mathrm{Cd} 16 / 32^{+}$cell population), and megakaryocyte-erythroid progenitor (MEP; CD34- $\mathrm{Lin}^{-} \mathrm{Sca}-1^{-} \mathrm{C}-\mathrm{Kit}{ }^{+} \mathrm{Cd} 16 / 32^{-}$cell population) cell counts are much lower in BM of Tmem30a ${ }^{-/-}$mice compared with WT mice. D: The

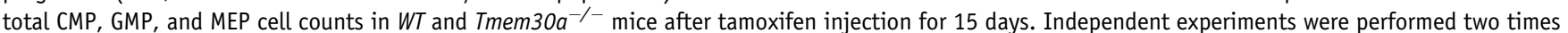
(C and D). E: Equal BM cell number $\left(5 \times 10^{5}\right)$ from Tmem30a-/- $\left(\right.$ CD45.2) and B6.SJL-Ptprca Pepc ${ }^{\text {b/Boyj }}$ (CD45.1) were mixed and injected into lethally irradiated recipients (CD45.1) via tail vein. Fluorescence-activated cell sorting analysis shows that in the same microenvironment Tmem30a deficiency significantly reduces viable cell percentage compared with CD45.1 cells in BM. The percentages of CD45.2 and CD45.1 are shown in the plot images. F: BM cells

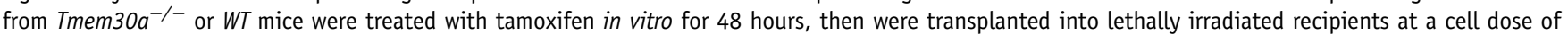
$1 \times 10^{6}$. Data are expressed as means \pm SD (B and $\left.\mathbf{D}\right) . n=3$ mice $(\mathbf{A}-\mathbf{E}) ; \mathrm{n}=5$ mice $(\mathbf{F})$. BMT, bone marrow transplantation.

resulted in an approximate $50 \%$ loss of BM cellularity at day 15 after tamoxifen injection. The pancytopenia phenotypes were also obviously observed in bone section from Tmem $30 a^{-l-}$ mice at day 15 . Compared with $W T$, photomicrographs showed that there were massive cell corpses in the BM section from Tmem $30 a^{-1-}$ mice, and most cells lost their normal morphologic structure and became debris (Figure 1C). In correlation, Tmem $30 a^{-1-}$ mice had a marked reduction of white blood cell counts in the peripheral blood and spleen (Figure 1, D and E). These results indicated that Tmem30a was essential for blood cell survival.

To define whether Tmem30a plays important roles for all lineage-committed cells, especially B cells and myeloid cells, immunohistochemistry against $\mathrm{Cd} 19$ and $\mathrm{Gr}-1$ was performed. Total B-cell $\left(\mathrm{Cd} 19^{+}\right)$and myeloid cell $\left(\mathrm{Gr}-1^{+}\right)$ counts were drastically decreased in the $\mathrm{Tmem}_{30 a^{-1-}}$ mouse BM section compared with the WT mouse BM section (Figure 2, A and B). Fluorescence-activated cell sorting 
A

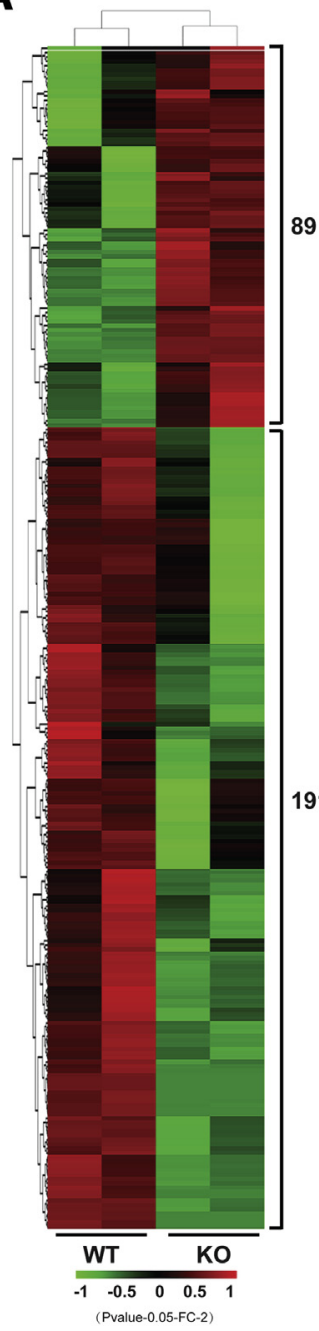

B

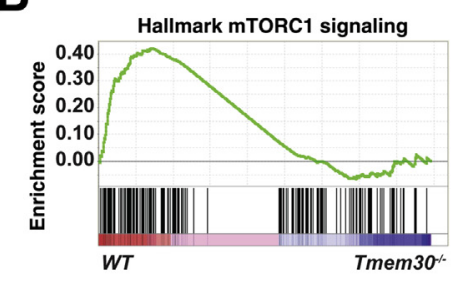

D

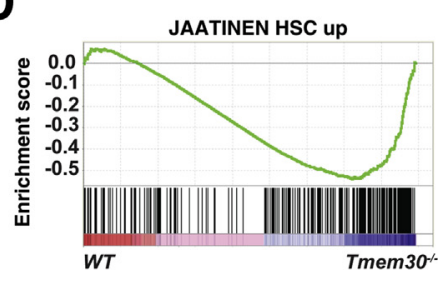

C

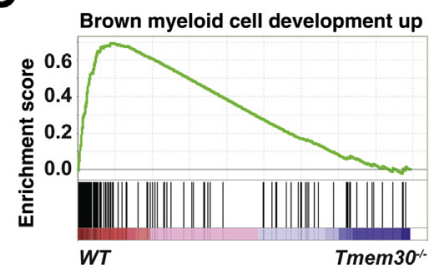

E

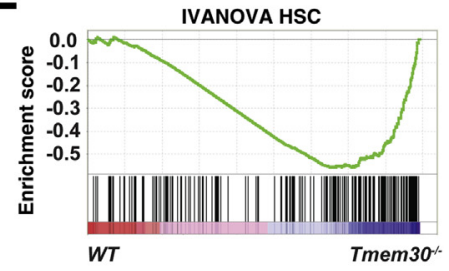

$\mathbf{F}$
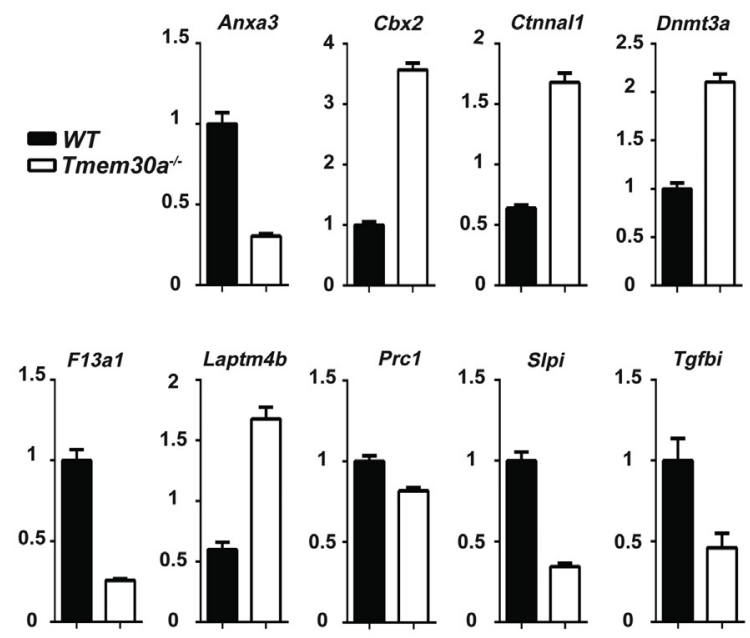

Figure 4 Gene expression signatures of $\mathrm{Tmem} 30 \mathrm{a}^{-/-}$hematopoietic stem cells (HSCs). A: Heat maps showing the expression changes of all 280 genes and hierarchical clustering of the genes in $\mathrm{Tmem} \mathrm{Oa}^{-/-} \mathrm{Lin}^{\text {low }} \mathrm{Sca}^{+}{ }^{+} \mathrm{C}-\mathrm{Kit}^{+}$(LSK) cells from the two biological replicates. Comparison of the global gene transcription profiles of LSK cells of wild-type (WT) and Tmem30a ${ }^{-/-}$mice at day 7 after tamoxifen injection. B-E: Gene Set Enrichment Analysis shows enrichment of gene sets up- or down-regulated in $\mathrm{Tmem}_{3} \mathrm{Oa}^{-1-}$ LSK cells. F: Expression level of genes from selected gene sets were confirmed using quantitative real-time PCR. Data are expressed as the means \pm SD of triplicate experiments performed at one time. K0, knockout; mTORC1, mammalian target of rapamycin complex 1.

(FACS) analysis further confirmed the results that either the percentages or total cell counts of $\mathrm{B}, \mathrm{T}$, and myeloid cells were dramatically decreased at days 15 and 28 after tamoxifen injection in Tmem $30 a^{-1-}$ mouse BM (Figure 2C).

To further determine whether Tmem30a deficiency perturbs B-cell development, three well-defined developmental stages of B cells were analyzed in BM with FACS, and immature cells were found to be the most sensitive and mature B cells less sensitive to Tmem30a deficiency (Figure 2, D and E). Taken together, Tmem30a was essential for B-cell survival and Tmem30a deficiency reduced B-cell progenitors and B-cell maturation at the developmental stages. The results also suggested that efficiency effects of Tmem30a deletion were time and cell type dependent.

Table 1 Gene Sets Related to Cell Survival, Proliferation, and Stemness

\begin{tabular}{|c|c|c|c|}
\hline Gene set & Size & Normalized enrichment score & Nominal $P$ value \\
\hline HALLMARK_MTORC1_SIGNALING & 192 & 1.51 & 0.00781 \\
\hline BROWN_MYELOID_CELL_DEVELOPMENT_UP & 138 & 2.38 & $<0.0001$ \\
\hline IVANOVA_HEMATOPOIESIS_STEM_CELL & 235 & -1.74 & $<0.0001$ \\
\hline JAATINEN_HEMATOPOIETIC_STEM_CELLL_UP & 274 & -1.72 & $<0.0001$ \\
\hline GAL_LEUKEMIC_STEM_CELL_DN & 207 & 1.85 & $<0.0001$ \\
\hline
\end{tabular}



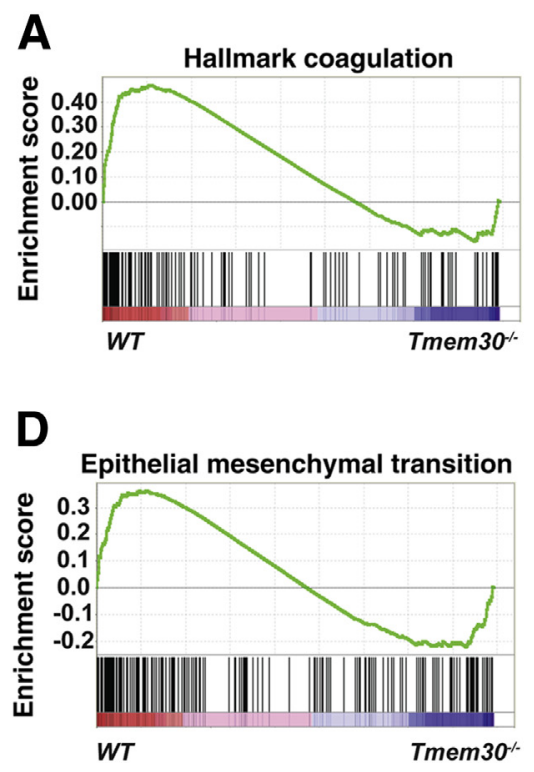

Tmem30a Is Essential for HSC and HPC Survival

The widespread effects of Tmem30a deficiency on blood lineages prompted us to examine its roles on HSCs and hematopoietic progenitor cells (HPCs). At 15 and 28 days after tamoxifen injection, both the WT and Tmem $30 a^{-/-}$mice were sacrificed and BM cells were harvested for LSK cell analysis with FACS (Figure 3A). Tmem30a deficiency caused a significant reduction of both the percentage and the absolute number of HSCs (Figure 3, A and B). Both Tmem $30 a^{-/-}$and WT BM still contained approximately similar numbers of LSK cells at day 7, but Tmem $30 a^{-1-}$ BM only contained approximately $50 \%$ of WT LSK cells at day 15 and approximately $30 \%$ of WT LSK cells at day 28 after tamoxifen injection (Figure 3B). In the HPC compartments, as expected, a decrease of CMPs, GMPs, and MEPs was detected in Tmem $30 a^{-/-}$mice compared with $W T$ controls (Figure 3, C and D). Among these HPCs, MEP cells were less sensitive to Tmem30a deficiency (Figure 3D).

Because CAG-CreER expression is not restricted in hematopoietic cells, the observed HSC phenotypes in Tmem $30 a^{-1-}$ mice may be due to a perturbed BM microenvironment. To investigate the possibility, Tmem $30 a^{-1-}$ (CD45.2) and B6.SJL-Ptprca Pepc ${ }^{b / B o y J}$ (CD45.1) BM cells, which were mixed at ratio of $1: 1$, were transplanted into lethally irradiated CD45.1 mice. Recipients received tamoxifen or vehicle at 12 weeks after BM transplantation (BMT). At day 15 after tamoxifen injection, recipients were sacrificed to harvest BM cells and the percentages of CD45.2 and CD45.1 were analyzed with FACS (Figure 3E). The mean ratio of CD45.2 versus CD45.1 was $29.2 \%$ to $47.5 \%$ in recipients received vehicle, but it was $12.8 \%$ to $66.5 \%$ in the tamoxifen injection group mice (Figure 3E). These results indicated that Tmem30a deficiency may directly cause leukocyte death. To avoid the BM microenvironment effects, BM cells from Tmem $30 a^{-/-}$or WT mice were treated with tamoxifen in vitro for 48 hours and then transplanted into lethally irradiated recipients at a cell dose of $1 \times 10^{6}$. Recipients that received Tmem $30 a^{-/-}$BM cells or no cell died within 10 days after irradiation, and only one mouse died in the group that received BM cells from WT mice (Figure 3F). This result indicates that deletion of Tmem30a in HSCs was sufficient to impair HSC survival.

Tmem30a Deletion Alters Multiple Signal Pathways in HSCS

To gain insights into the mechanism of HSC deficiency in Tmem $30 a^{-1-}$ mice, two independent sets of RNA

Table 2 Gene Sets Related to Important Biological Functions or Biological Processes

\begin{tabular}{lccc}
\hline Gene set & Size & Normalized enrichment score & Nominal $P$ value \\
\hline HALLMARK_COAGULATION & 131 & 1.58 & 0.00518 \\
HALLMARK_ANGIOGENESIS & 138 & 1.58 & 0.01329 \\
HALLMARK_COMPLEMENT & 180 & 1.35 & 0.01235 \\
HALLMARK_INTERFERON_ALPHA_RESPONSE & 87 & -1.85 & $<0.0001$ \\
HALLMARK_INTERFERON_GAMMA_RESPONSE & 182 & -1.47 & $<0.0001$ \\
BROWNE_INTERFERON_RESPONSIVE_GENES & 56 & -1.7 & $<0.0001$ \\
HALLMARK_INFLAMMATORY_RESPONSE & 193 & 1.21 & 0.03488 \\
HALLMARK_EPITHELIAL_MESENCHYMAL_TRANSITION & 192 & 1.3 & 0.01923 \\
HALLMARK_CHOLESTEROL_HOMEOSTASIS & 69 & 1.48 & 0.03578 \\
HALLMARK_GLYCOLYSIS & 193 & 1.27 & 0.01493 \\
\hline
\end{tabular}


A

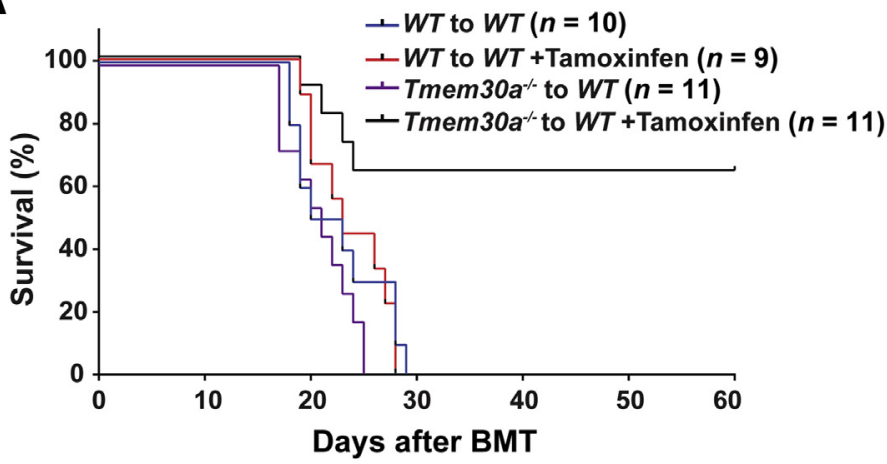

B

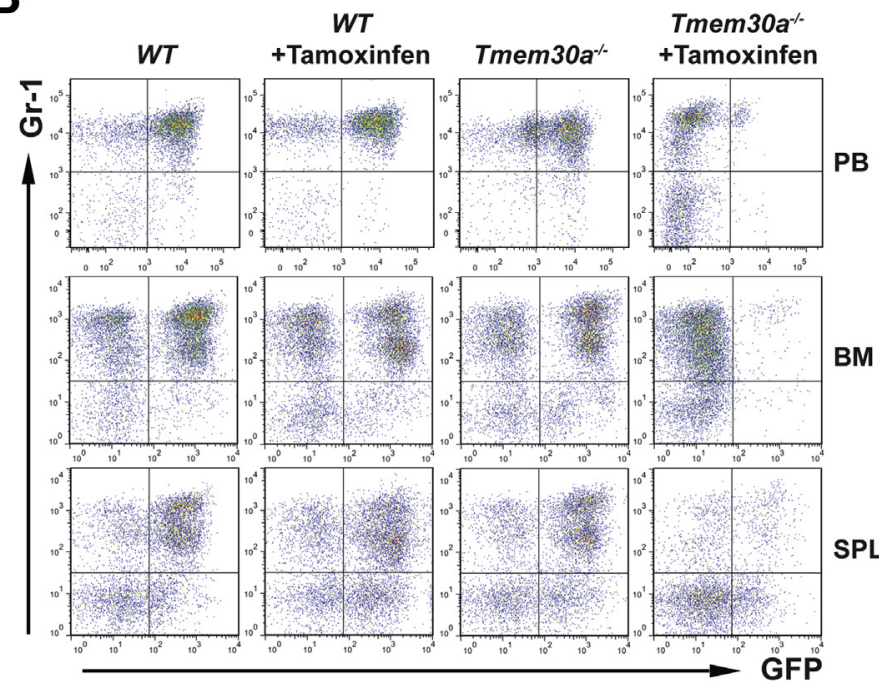

C

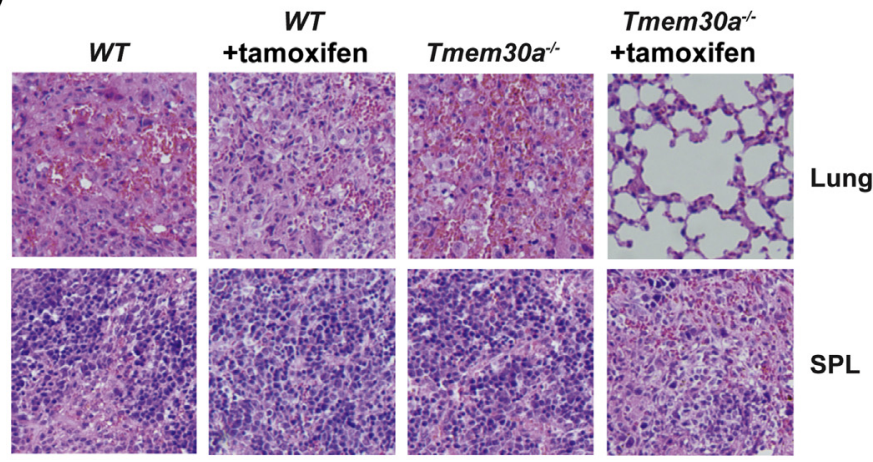

D

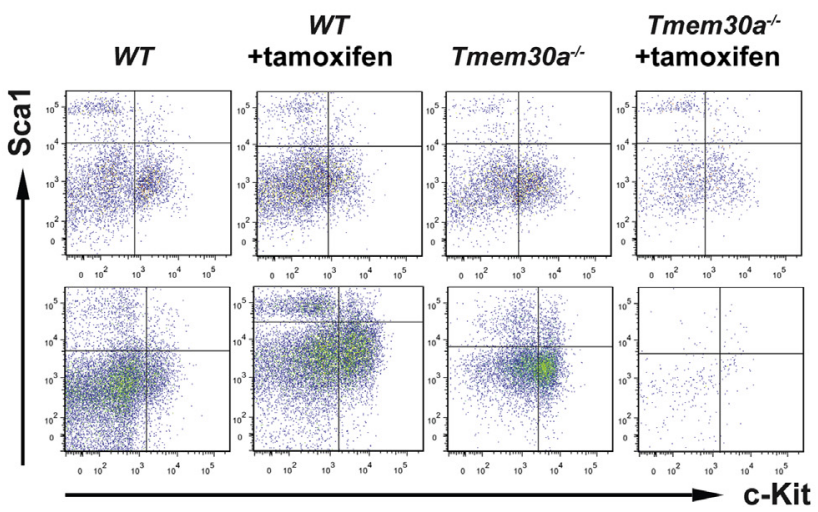

Figure 6 Tmem30a is also essential for BCR/ABL1transduced chronic myeloid leukemia in mice. A: KaplanMeier survival curves for recipients of puro murine stem cell virus-BCR/ABL1-internal ribosome entry siteenhanced green fluorescent protein (pMSCV-BCR/ABL1IRES-eGFP)-transduced bone marrow (BM) cells from wild-type (WT) or Tmem $30 a^{-/-}$donor mice. The recipient numbers of each group and survival days are indicated. Independent experiments were performed twice. B: Fluorescence-activated cell sorting analysis shows appearance of $\mathrm{GFP}^{+} \mathrm{Gr}-1^{+}$cells in peripheral blood (PB), BM, and spleen (SPL) of recipients of pMSCV-BCR/ABL1-IRES-eGFPtransduced BM cells from WT or Tmem $30 a^{-/-}$donor mice at day 13 after bone marrow transplantation (BMT; day 5 after tamoxifen injection). C: Photomicrographs of hematoxylin and eosin-stained lung and spleen sections from recipients of pMSCV-BCR/ABL1-IRES-eGFP-transduced BM cells from WT or Tmem $30 a^{-/-}$donor mice. D and E: FACS analysis (D) and total numbers (E) of leukemia stem cells $\left(\mathrm{GFP}^{+} \mathrm{Lin}^{-} \mathrm{C}^{-}\right.$ $\mathrm{Kit}^{+} \mathrm{Sca}-1^{+}$) in BM of recipients of BM cells of $W T$ or Tmem $30 a^{-1-}$ donor mice transduced with pMSCV-BCR/ ABL1-IRES-eGFP, 8 days after BMT and before tamoxifen injection and 13 days after BMT ( 5 days after tamoxifen injection). Data are expressed as means \pm SD (E). 
sequencing were performed for gene profiling analysis. BM cells from $\mathrm{Tmem}_{30 a^{-1-}}$ mice and their littermates, which were treated with tamoxifen for 7 days, were harvested and LSK cells were subsequently sorted with FACS. Total RNA was isolated, reverse transcribed to cDNA, and amplified. RNA sequencing was performed with the Illumina MiSeq system. Genes were considered significantly altered based on a twofold or greater change in mean expression $(P<0.05)$. With these criteria, 280 genes were determined to be significantly altered. Among these genes, 89 genes were up-regulated and 191 genes were down-regulated in Tmem $30 a^{-1-}$ LSK cells (Figure 4A).

Results of whole transcriptome comparisons using GSEA showed that mammalian target of rapamycin (mTOR) complex 1 pathway gene set was down-regulated in Tmem $30 a^{-/-}$LSK cells (Figure 4B). Previous studies already demonstrated that the mTOR signal pathway was essential for HSC self-renewal and multilineage hematopoiesis and mTOR deficiency was sufficient to cause pancytopenia in mice. ${ }^{27}$ This result indicates that the pancytopenia in Tmem30a deficiency mice is partially caused by the impairment of mTOR signal pathway.

Interestingly, a myeloid cell development gene set was enriched and down-regulated in Tmem $30 a^{-l-}$ LSK cells (Figure 4C), indicating that the differentiation capability of HSCs without Tmem30a was limited. In correlation, two previously published HSC gene sets of HSC stemness were significantly enriched in Tmem $30 a^{-/-}$LSK cells but not WT LSK cells (Figure 4, D and E) ${ }^{28,29}$ In addition, another two gene sets, CBFA2T3 and LSC down, were also significantly enriched and down-regulated in Tmem $30 a^{-/-}$LSK cells (Table 1).

To confirm the RNA sequencing results, nine genes (Anxa3, Cbx2, Ctnnall, Dnmt3a, F13a1, Laptm4b, Prc1, Slpi, and Tgfbi), which were listed in the above-mentioned gene sets and had well-established functions related to HSCs, were selected. ${ }^{28-30}$ Consistent with RNA sequencing data, all nine genes were either up-regulated or downregulated in RT-PCR analysis (Figure 4F).

Previous studies have demonstrated that P4-ATPases were critical for blood coagulation. ${ }^{3}$ Significant enrichment of coagulation sets was also detected by GSEA (Figure 5A). More gene sets related to important biological processes, such as angiogenesis and epithelial mesenchymal transition, were also significantly enriched (Figure 5, B and $\mathrm{D}$, Table 2). The fundamental biological function of Tmem30a is to ensure plasma membrane asymmetry and its deficiency causes cell death. ${ }^{16,20}$ This phenotype is further supported by some significant enrichment of gene sets, such as interferon response and DNA repair (Figure 5C, Table 2).

\section{Tmem30a Is Also Essential for the Induction of CML by $\mathrm{BCR} / \mathrm{ABL} 1$}

Currently, CML is still an incurable disease. The main reason is that LSCs in CML are not sensitive to chemotherapy. ${ }^{22}$ Tmem $30 a$ is essential for blood cell survival, including HSCs in mice. To further investigate whether Tmem30a is also critical for LSC survival, a BCR/ABL1transduced CML mouse model was used. WT or Tmem $30 a^{-1-}$ donor BM cells were used for CML induction. Two recipient groups were further divided into four groups and treated with tamoxifen or vehicle at day 8 after BMT. In the group that received Tmem $30 a^{-1-}$ BM cells and tamoxifen treatment, only four recipients died of CML, and seven mice finally were leukemia cell free; all recipients in the other three groups died of CML within 4 weeks (Figure 6A). This defective disease phenotype was correlated with many fewer leukemia cells in peripheral blood, BM, and spleen at day 13 after BMT (day 5 after tamoxifen injection) (Figure 6B). In addition, the lungs and spleens of the mice in the Tmem $30 a^{-/-}$donor and tamoxifen treatment group were less severely infiltrated with leukemia cells compared with the lungs and spleens of the other mice (Figure 6C).

It is essential to completely remove LSCs to cure CML. To test whether loss of Tmem30a impairs LSCs, LSCs in BM of CML mice were quantified at day 8 (before tamoxifen injection) and day 13 (day 5 after tamoxifen injection) after BMT. At day 8, there was no significant difference of LSC count in BM between WT and Tmem $30 a^{-/-}$mice (Figure 6, D and E). This result indicated that there was no deficiency of Tmem $30 a^{-/-}$BM cells in BM cell engraftment and leukemia transformation. However, at day 5 after tamoxifen injection, the percentage and number of LSCs transformed from Tmem $30 a^{-1-}$ BM cells were significantly reduced compared with that in other group recipients (Figure 6, D and E). This result indicated that Tmem30a deficiency not only strongly impaired normal HSCs but also was required for LSC survival.

\section{Discussion}

In this study, we found that Tmem30a deficiency caused severe pancytopenia by impairing the survival of lineage-committed blood cells and HSCs in mice, and its deficiency also impaired the survival of BCR/ABL1-transduced CML LSCs in mice. Tmem30a deficiency caused a rapid BM failure in mice (Figure 1B). Apoptosis status of BM cells was examined at several time points after tamoxifen injection. Although an obvious BM cell count decrease was observed (Figure 1, B and C), no difference was found in apoptosis of available cells from WT and Tmem $30 a^{-/-}$mice (data not shown). Tmem30a deficiency causes a rapid cell death. ${ }^{16,20}$ Therefore, most biological events, such apoptosis and cell cycle, are difficult to determine in Tmem $30 a^{-1-}$ mice.

The leukocyte counts in WT mice were also reduced after tamoxifen injection (Figure 1B) because tamoxifen, which usually is used to treat and prevent some types of breast cancers by blocking the actions of estrogen, ${ }^{31}$ also has cytotoxic effects on leukocytes. Compared with lineagecommitted blood cells, HSCs were less sensitive to the cytotoxicity caused by tamoxifen (Figure 3B). Therefore, the total HSC count increased at day 15 compared with that 
at day 7 after tamoxifen injection in the $W T$ group mice, whereas the HSC count in the Tmem $30 a^{-1-}$ group mice decreased at all examined time points (Figure 3B). Interestingly, not all lineage-committed cells were equally sensitive to Tmem30a deletion. Among B-cell development stages, pre- and pro- as well as immature B cells were more sensitive to Tmem30a deficiency compared with mature B cells (Figure 2D). Among HPCs, MEP cells were less sensitive to Tmem30a deficiency compared with CMP and GMP (Figure 3D).

To understand the molecular mechanisms of the pancytopenia, gene profiling for Tmem $30 a^{-/-}$LSK cells was performed. One critical prosurvival signaling gene set of mTOR was significantly down-regulated in $\mathrm{Tmem}_{3} \mathrm{Oa}^{-/-}$cells (Figure 4B). mTOR deficiency alone is sufficient to cause pancytopenia in mouse. ${ }^{27}$ Unexpectedly, two gene sets related to HSC stemness were highly up-regulated in Tmem30a ${ }^{-1-}$ LSK cells (Figure 4, D and E). The increased expression of these genes might be a compensatory effect of the increased death of LSK cells in Tmem $30 a^{-1-}$ mice. In correlation, Tmem $30 a^{-/-}$LSK cells displayed a diminished expression of myeloid differentiation relation genes (Figure 4, $\mathrm{C}$ and $\mathrm{F}$ ), such as genes in myeloid cell development up ${ }^{30}$ and CBFA2T3 target up ${ }^{32}$ gene sets. CBFA2T3 is a member of the myeloid translocation family genes. ${ }^{33}$ CBFA2T3 interacts with DNA-bound transcription factors, recruits a range of corepressors to facilitate transcriptional repression, and is involved in HSC differentiation. ${ }^{32}$ In addition, Tmem $30 a^{-/-}$ LSK cells displayed an increased level of interferon response genes (Figure 5, C and E). ${ }^{34,35}$ Interferon response genes are usually linked to growth inhibition, senescence, and apoptosis. ${ }^{36-40}$ Together, these results indicated that Tmem30a was involved in multiple signal pathways. A systematic exploration of the human interactome data also demonstrated that Tmem30a interacted with many other proteins, not only P4-ATPase family proteins. ${ }^{41,42}$

Unexpectedly, in BCR/ABL1-induced CML model, some recipients still died of CML (Figure 6A) after tamoxifen injection likely because the inducible deletion of Tmem $30 a$ by tamoxifen takes some time. In addition, tamoxifeninduced deletion of Tmem30a was not completed in all leukemia cells, including LSCs. This explanation was further confirmed with PCR from leukemia cell genomic DNA. PCR results showed that the Tmem30a gene was not deleted in the leukemia cells from mice that died of CML. If the recipient could overcome this critical period, it became leukemia cell free (Figure 6A). Of interest, LSCs were more sensitive to the loss of Tmem30a compared with normal HSCs. LSC count rapidly reduced at day 5 (Figure 6, D and E), but there was no significant decrease of HSC count at day 7 after tamoxifen injection. This may provide a time window for potential CML therapy by targeting Tmem30a. Although it is hard to directly target Tmem30a with compounds now, in the P4-APTase complex, the $\alpha$ subset, such as ATP8A1, ATP8B1, ATP11A, ATP11B, and ATP11C, is potentially targetable. ${ }^{4-45}$
Collectively, our results demonstrate that Tmem30a is essential for the survival of hematopoietic system cells and BCR/ABL1-transduced leukemia cells. Tmem30a deficiency results in rapid pancytopenia in mice and impairment of leukemia cell survival. These results highlight the roles of Tmem30a in the hematopoietic system.

\section{Acknowledgments}

We thank Prof. Yuquan Wei for management support and Dr. Robert Molday (University of British Columbia, Vancouver, BC, Canada) for Cdc50-7F4 antibody.

N.L. designed studies, performed experiments, and analyzed data; Y.Y. maintained mice and performed tamoxifen induction; C.L., Q.Q., C.P., and M.L. performed experiments; S.Y. and L.C. analyzed data; X.Z. designed studies and interpreted findings; Y.H. conceived and designed studies, analyzed data, and wrote the manuscript.

\section{Supplemental Data}

Supplemental material for this article can be found at https://doi.org/10.1016/j.ajpath.2018.02.015.

\section{References}

1. Cooper GM: Structure of the Plasma Membrane. Sunderland, MA, Sinauer Associates, 2000

2. Lopez-Marques RL, Theorin L, Palmgren MG, Pomorski TG: P4ATPases: lipid flippases in cell membranes. Pflugers Arch 2014 466:1227-1240

3. Leventis PA, Grinstein S: The distribution and function of phosphatidylserine in cellular membranes. Annu Rev Biophys 2010, 39: 407-427

4. Chen CY, Ingram MF, Rosal PH, Graham TR: Role for Drs2p, a Ptype ATPase and potential aminophospholipid translocase, in yeast late Golgi function. J Cell Biol 1999, 147:1223-1236

5. Darland-Ransom M, Wang X, Sun CL, Mapes J, Gengyo-Ando K, Mitani S, Xue D: Role of C. elegans TAT-1 protein in maintaining plasma membrane phosphatidylserine asymmetry. Science 2008, 320:528-531

6. Wang L, Beserra C, Garbers DL: A novel aminophospholipid transporter exclusively expressed in spermatozoa is required for membrane lipid asymmetry and normal fertilization. Dev Biol 2004, 267: 203-215

7. Kato U, Inadome H, Yamamoto M, Emoto K, Kobayashi T, Umeda M: Role for phospholipid flippase complex of ATP8A1 and CDC50A proteins in cell migration. J Biol Chem 2013, 288:4922-4934

8. Martin-Hernandez E, Rodriguez-Garcia ME, Camacho A, MatillaDuenas A, Garcia-Silva MT, Quijada-Fraile P, Corral-Juan M, TejadaPalacios P, de Las Heras RS, Arenas J, Martin MA, Martinez-Azorin F: New ATP8A2 gene mutations associated with a novel syndrome: encephalopathy, intellectual disability, severe hypotonia, chorea and optic atrophy. Neurogenetics 2016, 17:259-263

9. Onat OE, Gulsuner S, Bilguvar K, Nazli Basak A, Topaloglu H, Tan M, Tan U, Gunel M, Ozcelik T: Missense mutation in the ATPase, aminophospholipid transporter protein ATP8A2 is associated with cerebellar atrophy and quadrupedal locomotion. Eur J Hum Genet 2013, 21:281-285

10. Levano K, Punia V, Raghunath M, Debata PR, Curcio GM, Mogha A Purkayastha S, McCloskey D, Fata J, Banerjee P: Atp8al deficiency is associated with phosphatidylserine externalization in hippocampus and 
delayed hippocampus-dependent learning. J Neurochem 2012, 120: 302-313

11. Cacciagli P, Haddad MR, Mignon-Ravix C, El-Waly B, Moncla A, Missirian C, Chabrol B, Villard L: Disruption of the ATP8A2 gene in a patient with a $t(10 ; 13)$ de novo balanced translocation and a severe neurological phenotype. Eur J Hum Genet 2010, 18: $1360-1363$

12. Siggs OM, Arnold CN, Huber C, Pirie E, Xia Y, Lin P, Nemazee D, Beutler B: The P4-type ATPase ATP11C is essential for B lymphopoiesis in adult bone marrow. Nat Immunol 2011, 12:434-440

13. Yabas M, Teh CE, Frankenreiter S, Lal D, Roots CM, Whittle B, Andrews DT, Zhang Y, Teoh NC, Sprent J, Tze LE, Kucharska EM, Kofler J, Farell GC, Broer S, Goodnow CC, Enders A: ATP11C is critical for the internalization of phosphatidylserine and differentiation of B lymphocytes. Nat Immunol 2011, 12:441-449

14. Siggs OM, Schnabl B, Webb B, Beutler B: X-linked cholestasis in mouse due to mutations of the P4-ATPase ATP11C. Proc Natl Acad Sci U S A 2011, 108:7890-7895

15. Yabas M, Coupland LA, Cromer D, Winterberg M, Teoh NC, D'Rozario J, Kirk K, Broer S, Parish CR, Enders A: Mice deficient in the putative phospholipid flippase ATP11C exhibit altered erythrocyte shape, anemia, and reduced erythrocyte life span. J Biol Chem 2014, 289:19531-19537

16. Zhang L, Yang Y, Li S, Zhang S, Zhu X, Tai Z, Yang M, Liu Y, Guo X, Chen B, Jiang Z, Lu F, Zhu X: Loss of Tmem30a leads to photoreceptor degeneration. Sci Rep 2017, 7:9296

17. Baldridge RD, Graham TR: Identification of residues defining phospholipid flippase substrate specificity of type IV P-type ATPases. Proc Natl Acad Sci U S A 2012, 109:E290-E298

18. Zhou X, Graham TR: Reconstitution of phospholipid translocase activity with purified Drs2p, a type-IV P-type ATPase from budding yeast. Proc Natl Acad Sci U S A 2009, 106:16586-16591

19. Coleman JA, Kwok MC, Molday RS: Localization, purification, and functional reconstitution of the P4-ATPase Atp8a2, a phosphatidylserine flippase in photoreceptor disc membranes. J Biol Chem 2009, 284:32670-32679

20. Liu L, Zhang L, Zhang L, Yang F, Zhu X, Lu Z, Yang Y, Lu H, Feng L, Wang Z, Chen H, Yan S, Wang L, Ju Z, Jin H, Zhu X: Hepatic Tmem30a deficiency causes intrahepatic cholestasis by impairing expression and localization of bile salt transporters. Am J Pathol 2017, $187: 2775-2787$

21. Doulatov S, Notta F, Laurenti E, Dick JE: Hematopoiesis: a human perspective. Cell Stem Cell 2012, 10:120-136

22. Hu Y, Chen Y, Douglas L, Li S: beta-Catenin is essential for survival of leukemic stem cells insensitive to kinase inhibition in mice with BCR-ABL-induced chronic myeloid leukemia. Leukemia 2009, 23 : $109-116$

23. Hayashi S, McMahon AP: Efficient recombination in diverse tissues by a tamoxifen-inducible form of Cre: a tool for temporally regulated gene activation/inactivation in the mouse. Dev Biol 2002, 244: 305-318

24. Hu Y, Zheng M, Gali R, Tian Z, Topal Gorgun G, Munshi NC, Mitsiades CS, Anderson KC: A novel rapid-onset high-penetrance plasmacytoma mouse model driven by deregulation of cMYC cooperating with KRAS12V in BALB/c mice. Blood Cancer J 2013, 3:e156

25. Mootha VK, Lindgren CM, Eriksson KF, Subramanian A, Sihag S, Lehar J, Puigserver P, Carlsson E, Ridderstrale M, Laurila E, Houstis N, Daly MJ, Patterson N, Mesirov JP, Golub TR, Tamayo P, Spiegelman B, Lander ES, Hirschhorn JN, Altshuler D, Groop LC: PGC-1alpharesponsive genes involved in oxidative phosphorylation are coordinately downregulated in human diabetes. Nat Genet 2003, 34:267-273

26. Subramanian A, Tamayo P, Mootha VK, Mukherjee S, Ebert BL, Gillette MA, Paulovich A, Pomeroy SL, Golub TR, Lander ES, Mesirov JP: Gene set enrichment analysis: a knowledge-based approach for interpreting genome-wide expression profiles. Proc Natl Acad Sci U S A 2005, 102:15545-15550
27. Guo F, Zhang S, Grogg M, Cancelas JA, Varney ME, Starczynowski DT, Du W, Yang JQ, Liu W, Thomas G, Kozma S, Pang Q, Zheng Y: Mouse gene targeting reveals an essential role of mTOR in hematopoietic stem cell engraftment and hematopoiesis. Haematologica 2013, 98:1353-1358

28. Ivanova NB, Dimos JT, Schaniel C, Hackney JA, Moore KA, Lemischka IR: A stem cell molecular signature. Science 2002, 298: 601-604

29. Jaatinen $T$, Hemmoranta $H$, Hautaniemi S, Niemi J, Nicorici D, Laine J, Yli-Harja O, Partanen J: Global gene expression profile of human cord blood-derived CD133+ cells. Stem Cells 2006, 24: 631-641

30. Brown AL, Wilkinson CR, Waterman SR, Kok CH, Salerno DG, Diakiw SM, Reynolds B, Scott HS, Tsykin A, Glonek GF, Goodall GJ, Solomon PJ, Gonda TJ, D'Andrea RJ: Genetic regulators of myelopoiesis and leukemic signaling identified by gene profiling and linear modeling. J Leukoc Biol 2006, 80:433-447

31. Jordan VC: Fourteenth Gaddum Memorial Lecture: a current view of tamoxifen for the treatment and prevention of breast cancer. Br J Pharmacol 1993, 110:507-517

32. Chyla BJ, Moreno-Miralles I, Steapleton MA, Thompson MA, Bhaskara S, Engel M, Hiebert SW: Deletion of Mtg16, a target of t(16; 21), alters hematopoietic progenitor cell proliferation and lineage allocation. Mol Cell Biol 2008, 28:6234-6247

33. Rossetti S, Hoogeveen AT, Esposito J, Sacchi N: Loss of MTG16a (CBFA2T3), a novel rDNA repressor, leads to increased ribogenesis and disruption of breast acinar morphogenesis. J Cell Mol Med 2010, $14: 1358-1370$

34. Christian SL, Zu D, Licursi M, Komatsu Y, Pongnopparat T, Codner DA, Hirasawa K: Suppression of IFN-induced transcription underlies IFN defects generated by activated Ras/MEK in human cancer cells. PLoS One 2012, 7:e44267

35. Thomas E, Gonzalez VD, Li Q, Modi AA, Chen W, Noureddin M, Rotman Y, Liang TJ: HCV infection induces a unique hepatic innate immune response associated with robust production of type III interferons. Gastroenterology 2012, 142:978-988

36. Xu H, Xian J, Vire E, McKinney S, Wei V, Wong J, Tong R, Kouzarides T, Caldas C, Aparicio S: Up-regulation of the interferonrelated genes in BRCA2 knockout epithelial cells. J Pathol 2014, 234:386-397

37. Stawowczyk M, Van Scoy S, Kumar KP, Reich NC: The interferon stimulated gene 54 promotes apoptosis. J Biol Chem 2011, 286: $7257-7266$

38. Andersen JB, Li XL, Judge CS, Zhou A, Jha BK, Shelby S, Zhou L, Silverman RH, Hassel BA: Role of 2-5A-dependent RNase-L in senescence and longevity. Oncogene 2007, 26:3081-3088

39. Couzinet A, Tamura K, Chen HM, Nishimura K, Wang Z, Morishita Y, Takeda K, Yagita H, Yanai H, Taniguchi T, Tamura T: A cell-type-specific requirement for IFN regulatory factor 5 (IRF5) in Fas-induced apoptosis. Proc Natl Acad Sci U S A 2008, 105: $2556-2561$

40. Lee SB, Rodriguez D, Rodriguez JR, Esteban M: The apoptosis pathway triggered by the interferon-induced protein kinase PKR requires the third basic domain, initiates upstream of Bcl-2, and involves ICE-like proteases. Virology 1997, 231:81-88

41. Huttlin EL, Ting L, Bruckner RJ, Gebreab F, Gygi MP, Szpyt J, Tam S, Zarraga G, Colby G, Baltier K, Dong R, Guarani V, Vaites LP, Ordureau A, Rad R, Erickson BK, Wuhr M, Chick J, Zhai B, Kolippakkam D, Mintseris J, Obar RA, Harris T, ArtavanisTsakonas S, Sowa ME, De Camilli P, Paulo JA, Harper JW, Gygi SP: The BioPlex Network: a systematic exploration of the human interactome. Cell 2015, 162:425-440

42. Huttlin EL, Bruckner RJ, Paulo JA, Cannon JR, Ting L, Baltier K, Colby G, Gebreab F, Gygi MP, Parzen H, Szpyt J, Tam S, Zarraga G, Pontano-Vaites L, Swarup S, White AE, Schweppe DK, Rad R, Erickson BK, Obar RA, Guruharsha KG, Li K, Artavanis-Tsakonas S, 
Gygi SP, Harper JW: Architecture of the human interactome defines protein communities and disease networks. Nature 2017, 545:505-509

43. Lin RJ, Su ZZ, Liang SM, Chen YY, Shu XR, Nie RQ, Wang JF, Xie SL: Role of circulating fibrocytes in cardiac fibrosis. Chin Med J (Engl) 2016, 129:326-331

44. Chen J, Wu X, Yao L, Yan L, Zhang L, Qiu J, Liu X, Jia S, Meng A: Impairment of cargo transportation caused by gbf1 mutation disrupts vascular integrity and causes hemorrhage in Zebrafish embryos. J Biol Chem 2017, 292:2315-2327

45. Jaworski E, Narayanan A, Van Duyne R, Shabbeer-Meyering S, Iordanskiy S, Saifuddin M, Das R, Afonso PV, Sampey GC, Chung M, Popratiloff A, Shrestha B, Sehgal M, Jain P, Vertes A, Mahieux R, Kashanchi F: Human T-lymphotropic virus type 1-infected cells secrete exosomes that contain Tax protein. J Biol Chem 2014, 289:22284-22305 